\title{
Investigation of the influence of coolant-lubricant modification on selected effects of pull broaching
}

\author{
Krzysztof Adamczuk ${ }^{1}$, Stanisław Legutko, ${ }^{2, *}$, Alicja Laber $^{1}$, and Wojciech Serwa ${ }^{1}$ \\ ${ }^{1}$ Faculty of Mechanical Engineering, University of Zielona Gora, 4 Prof. Z. Szafrana Street, 65-516 Zielona Gora, Poland \\ ${ }^{2}$ Faculty of Mechanical Engineering and Management, Poznan University of Technology 3 Piotrowo Street, 60-965 Poznan, Poland
}

\begin{abstract}
The paper presents the results of testing the wear of the tool (pull broach) and a gear wheel splineway surface roughness after the friction node of pull broach/gear wheel (CuSn12Ni2) had been lubricated with metal machining oil and the same oil modified with chemically active exploitation additive. To designate the influence of modifying metal machining oil by the exploitation additive on the lubricating properties, anti-wear and antiseizure indicators have been appointed. Exploitation tests have proved purposefulness of modifying metal machining oil. Modification of the lubricant has contributed to reduction of the wear of the tools - pull broaches and to reduction of roughness of the splineway surfaces.
\end{abstract}

\section{Introduction}

Strong worldwide competition in production industry forces producers to constantly improve and seek solutions reducing production costs while maintaining or raising the product quality [1-4]. Reduction of production costs allows for reduction of the price of ready-made products and, consequently to become an attractive supplier in the market. However, high quality of products must be maintained because its lowering may result in drop of sales of products. Properly designed and generated surface structure can, for example, minimize the friction coefficient. Modifications aiming at improvement of the surface quality are a result of thermal and mechanical loads of the process of machining, e.g. tool wear OUPN system stability or machining parameters. The machined surface is generated on the basis of the tool profile and the actual surface profiles depends on various disturbances in the process of machining $[5,6]$.

In order to improve the working conditions of highly loaded gears, thin and hard anti-wear coatings were applied [7-10]. Identification of lubrication conditions in concentrated contact have also been dealt with [11,12].

Fontanari and others [13] have examined the influence of the friction combination of $\mathrm{CuSn} 12$ bronze / $42 \mathrm{CrMo} 4 \mathrm{~V}$ steel on the tribological properties of a worm gear. The tests have been performed with various loads of the friction node on a friction path of about $1800 \mathrm{~km}$, interrupting it periodically in order to measure the sample mass. Basing on the tests, curves of wear as a function of the friction path have been made. Surface damages have been analysed with the use of scanning microscopy. Various pinholes and splinters have been found on the friction surface; their size depended on the load applied to the friction pair.

The influence of load, speed and kind of lubricating agent on the tribological properties of CuSn 10 bronze has also been tested [14]. Basing on the tests, the influence of those parameters on the friction coefficient, friction area temperature and the wear of the friction node has been determined. The tribological properties are also influenced by the environment. $T$. Kucukomeroglu and others [15] have found that the tribological properties of the CuSn10 alloy vary depending on the conditions of testing. They have compared the results obtained in vacuum to those obtained in atmospheric conditions. The test results have shown that the friction coefficient increases in vacuum and wear resistance grows. A. Laber and others [16] have also performed tests using casting bronze and sintered bronze CuSn10Ni2, for the friction node. The friction node has been greased with various lubricants modified with chemically active exploitation additive. Modification of the oils has variously influenced the lubricating properties (standardized tests, tester T-02) and tribological properties (not standardized tests, tester $\mathrm{T}-05$ ) of the bronzes under investigation.

The wear of wedges of pull broaches for forming internal surfaces has also been investigated by $\mathrm{K}$. Wieczorowski and others [17]. The authors have found excessive wear on the side edges of the pull broaches, which has been the reason of damages of the splineway side surfaces.

The purpose of the present investigation was to solve the problem of wear of pull broaches in the process of pull broaching of the splineways of gear wheels made of $\mathrm{CuSn} 12 \mathrm{Ni} 2$ bronze and to reduce the value of roughness parameters of the splineway. Modification of the lubricant (metal machining oil) with chemically active

\footnotetext{
* Corresponding author: stanislaw.legutko@put.poznan.pl
} 
exploitation additive was aimed at improvement of the working conditions of the pull broaches.

\section{Experiment}

\subsection{Test materials}

The material taken to the tests was $\mathrm{CuSn} 12 \mathrm{Ni} 2$ bronze with the following mechanical properties: Brinell hardness $110 \mathrm{HB}$, tensile strength $\mathrm{Rm}=550 \mathrm{MPa}$. This grade of bronze is very resistant to static loads, corrosion, abrasion and elevated temperatures. It has very good cast ability. In Table 1 , one can find a view of the structure and the average chemical composition of the CuSn12Ni2 bronze.

Table 1. Chemical composition and metallographic structure of CuSn12Ni2 bronze.

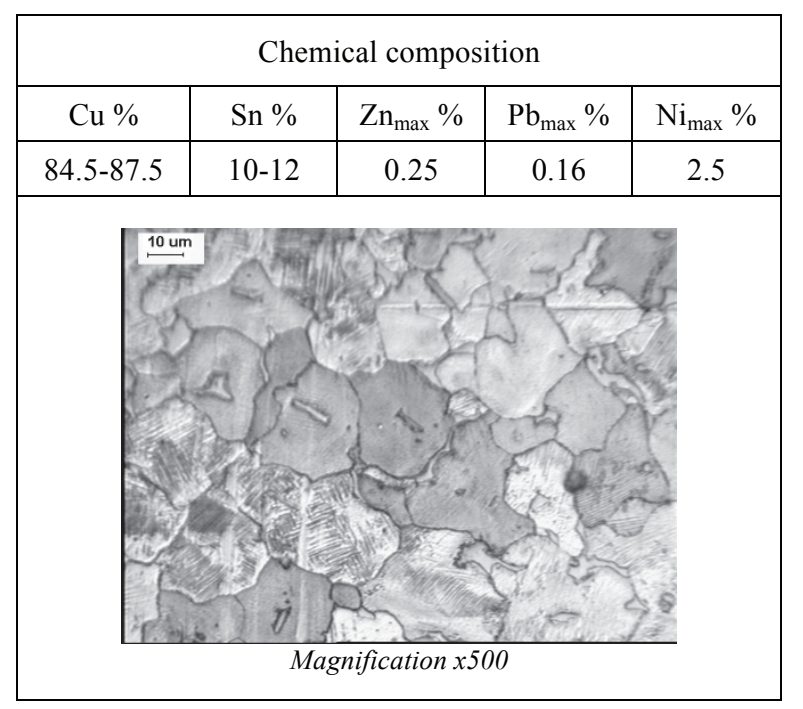

For comparative analysis of the pull broaches, two tools with the same dimensions and parameters in the initial condition have been selected (Fig. 1). Using those tools, 6000 splineways in gear wheels have been made.

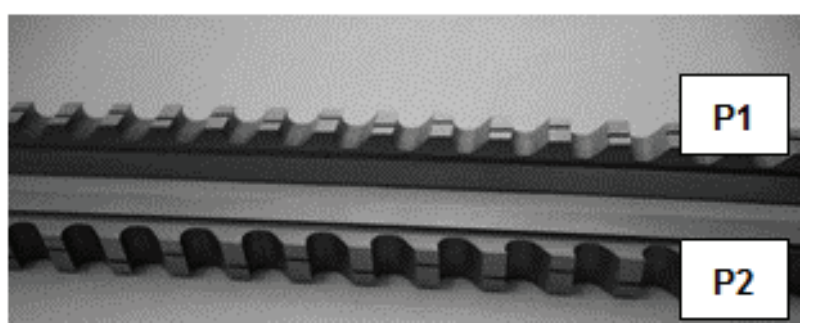

Fig. 1. Pull broaches used in the tests.

The lubricating properties were tested in the presence of the lubricating agent for metal machining with the following physical and chemical properties: density at $20^{\circ} \mathrm{C}<865 \mathrm{~kg} / \mathrm{m}^{3}$, kinematic viscosity at $40^{\circ} \mathrm{C}=22$ $\mathrm{mm}^{2} / \mathrm{s}$, ignition temperature $190^{\circ} \mathrm{C}$, flowing temperature $-15^{\circ} \mathrm{C}$

The lubricating agent has been modified with an exploitation additive with the following properties: kinematic viscosity at $40^{\circ} \mathrm{C}=117 \mathrm{~mm}^{2} / \mathrm{s}$, kinematic viscosity at $100^{\circ} \mathrm{C}=5.63 \mathrm{~mm}^{2} / \mathrm{s}$.
Table 2 shows the designations of the tested pull broaches according to the producer.

\begin{tabular}{|c|c|}
\hline \multicolumn{2}{|c|}{ L.p. } \\
\hline 1 & 2 \\
\hline \multicolumn{2}{|c|}{ Our own designation } \\
\hline P1 P2 \\
\hline \multicolumn{2}{|c|}{ Producer's designation } \\
\hline 6P9x3.7x2.8 RN1060 & 6P9x3.7x2.8 RN1060 \\
Id.-Nr:5980640; SC 6-5-2 & Id.-Nr:5980640; SC 6-5-2 \\
RL16-40 250.3095 11-0221 & RL16-40 250.3095 11-0221 \\
6; SWZ 08/11 & 3; SWZ 08/11 \\
\hline \multicolumn{2}{|c|}{ The cooling - lubricating agent applied } \\
\hline Industrial lubricating oil & Modified lubricating oil \\
\hline
\end{tabular}

The additive is conveyed to the friction zone by means of the lubricating agent forming a boundary layer on the friction surfaces; the layer is created as result of chemisorption; the layer has high resistance to high dynamic and temperature loads and resistance to breaking.

a)

b)

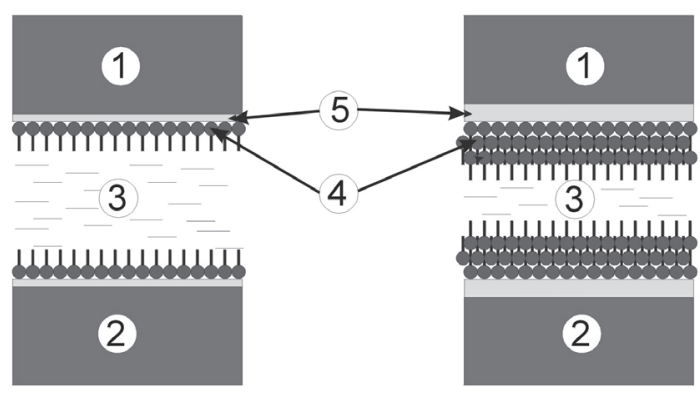

Fig. 2. A model of friction node lubricated with: a) market available lubricating agent, b) market available lubricating agent with exploitation additive; 1, 2 - friction elements, 3 lubricating agent, 4 - boundary layer formed due to physical sorption, 5 - boundary layer formed due to chemisorption [18].

\subsection{Methodology of investigation}

Tests of the lubricating properties of the lubricant for metal machining have been performed according to PN$76 / \mathrm{C}-04147$ by means of a four ball apparatus. The following indices of the lubrication properties: weld point $P_{\mathrm{z}}$; index of wear under load $\mathrm{I}_{\mathrm{h}}$; not seizing load $P_{n}$; seizing load $P_{t}$; limit wear load $G_{o z}$, and the average diameter of defects. The determination of the $P_{z}, P_{n}$ and $I_{h}$ indices has been effected with stepwise increasing load to the moment of welding of the friction node. The $P_{t}$ index has been determined with the friction node load increasing from 0 to $800 \mathrm{daN}$ at the rate of $408.8 \mathrm{~N} / \mathrm{s}$ the determination of the limit wear load with the friction node load of $150 \mathrm{daN}$. A view of the four ball apparatus and a diagram of the friction node can be seen in Fig. 3.

The assessment of the effect of the lubricating agent modification in order to improve the working conditions of the pull broaches required tests under exploitation conditions. Exploitation tests have been performed with the use of two CNC broaching machines (Fig. 4). In one of them, $\mathrm{CNC} 1$, metal machining oil has been applied; in the other, $\mathrm{CNC} 2$, the same oil modified with the exploitation additive. The friction node for the $\mathrm{CNC1}$ 
machine consisted of a $\mathrm{CuSn} 12 \mathrm{Ni} 2$ gear wheel/P1 pull broach; the node for the $\mathrm{CNC} 2$ machine included a gear wheel of CuSn12Ni2 bronze/ pull broach P2 (Fig. 5). After the exploitation tests, the wear of the pull broaches has been analysed with the use of a workshop microscope, MWD, with the magnification of 50 times.

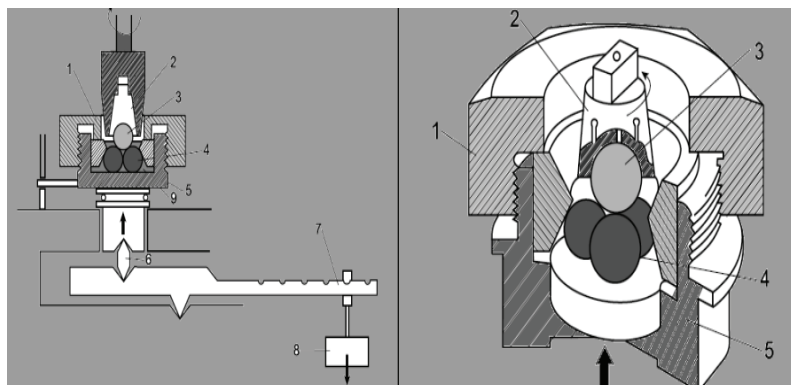

Fig. 3. The four ball apparatus: kinematic diagram of the friction node: 1 - cover fixing the bottom balls, 2 - upper ball holder, 3 - upper ball (turned one), 4 - bottom balls (immobile), 5 - vessel with the tested oil, 6 - prism, 7 - lever, 8 - weight, 9 -tested oil; b) a diagram of the friction node.
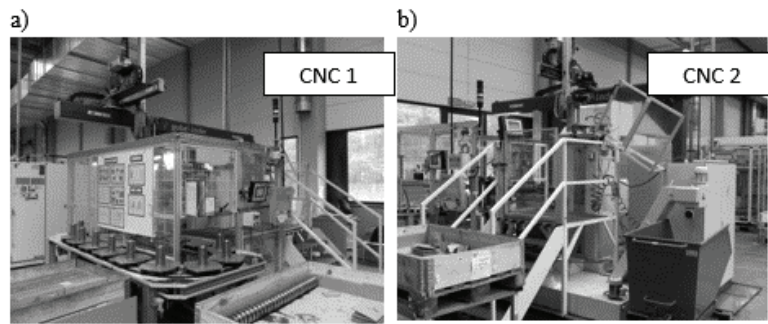

Fig. 4. Broaching machines used in the exploitation tests: a) with metal machining oil, b) with metal machining oil modified with exploitation additive.

The geometry of the cutting wedges of the broaches has been determined by means of a contour device made by Mahr, model MahrSurf XC 20 PCV. The collected results of dimension values for the individual tools have allowed us to perform a comparative analysis in respect of changes in the geometry of the tested tools. a)

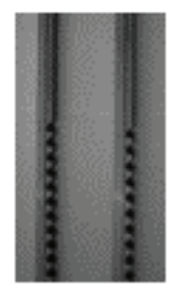

b)

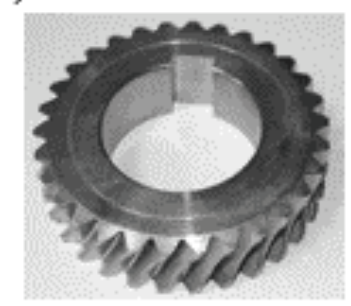

Fig. 5. Elements of the friction node: a) pull broach, b) gear wheel.

\section{Investigation results}

\subsection{Results of the tests of lubricating properties}

In Tables 3 and 4 , one can find the results of lubricating property tests of the lubricant under investigation and of the same lubricant modified with exploitation additive.
Basing on the test results shown in Tables 3 and 4, it has been determined that modifying the metal machining oil with chemically active additive has not influenced improvement of the weld point $P z$, and not seizing load $P n$. On the other hand, an increase of the seizing load index $P_{t}$, has been obtained (from the value of 201.99 to the value of $270.23 \mathrm{daN}$ ). As a result of the modification the lubricating layer durability has been improved by $34 \%$. The limit wear load $G_{o z}$, has also been found to grow from the value of 96.30 to the value of 138.67 $\mathrm{daN} / \mathrm{mm}^{2}$, which has contributed to the improvement of anti-wear properties of the lubricant.

Table 3. Lubricating properties of the lubricants under investigation.

\begin{tabular}{|c|c|c|c|c|}
\hline Lubricant & $\begin{array}{c}\boldsymbol{P}_{\boldsymbol{t}} \\
{[\mathbf{d a N}]}\end{array}$ & $\begin{array}{c}\boldsymbol{P}_{\boldsymbol{z}} \\
{[\mathbf{d a N}]}\end{array}$ & $\begin{array}{c}\boldsymbol{P}_{\boldsymbol{n}} \\
{[\mathbf{d a N}]}\end{array}$ & $\begin{array}{c}\boldsymbol{I}_{\boldsymbol{h}} \\
{[\mathbf{d a N}]}\end{array}$ \\
\hline $\begin{array}{c}\text { Metal machining } \\
\text { oil }\end{array}$ & $\begin{array}{c}201.99 \\
\pm 10\end{array}$ & 500 & 100 & $\begin{array}{c}62.509 \\
\pm 25\end{array}$ \\
\hline $\begin{array}{c}\text { Metal machining } \\
\text { oil + exploitation } \\
\text { additive }\end{array}$ & $\begin{array}{c}270,23 \\
\pm 13.5\end{array}$ & $\begin{array}{c}315 \\
\pm 15.7\end{array}$ & 80 & $\begin{array}{c}62.291 \\
\pm 3\end{array}$ \\
\hline
\end{tabular}

Table 4. Values of the limit wear load, $\mathrm{G}_{\mathrm{oz}}$, of the agents under investigation.

\begin{tabular}{|c|c|}
\hline Lubricant & $\boldsymbol{G}_{\boldsymbol{o z}}\left[\mathbf{d a N} / \mathbf{m m}^{\mathbf{2}}\right]$ \\
\hline Metal machining oil & $96.30 \pm 4.8$ \\
\hline $\begin{array}{c}\text { Metal machining oil + exploitation } \\
\text { additive }\end{array}$ & $138.67 \pm 6.9$ \\
\hline
\end{tabular}

\subsection{Verification tests}

The lubricant influence on the tool wear has been determined by measurement of the changes of the geometry of the tool cutting edges. For that purpose, measurements have been performed and then the following dimensional magnitudes have been compared to those of a new tool (Fig. 6):

- clearance angle $(\alpha)$;

- rake angle $(\gamma)$;

- the angle of the linear section of the chip groove $(\beta)$;

- cutting edge rounding radius $(r)$;

- chip groove rounding radius $(R)$;

- height increase of the individual edges $(a)$.

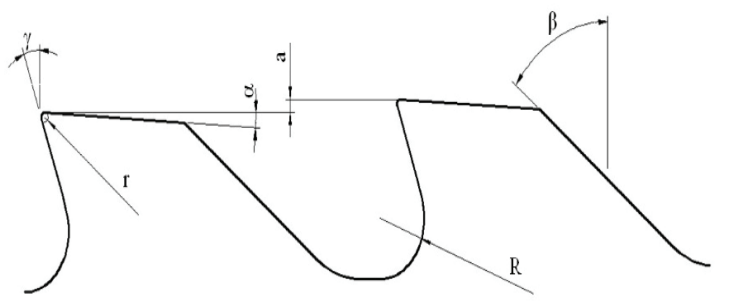

Fig. 6. Designation of the compared dimensions of the pull broach cutting edges: $a$ - height increase of the individual edges; $\alpha$-clearance angle; $\beta$ - angle of the linear section of the chip groove; $\gamma$ - rake angle; $r$ - radius of the cutting edge roundoing; $R$-radius of the chip groove rounding.

The measurements of the dimensional values of the geometry have been performed on two sections: D1 and $\mathrm{D} 2$, at the beginning of the tool (8 first wedges - the first 
measurement section) and in its end part (wedges 26 to 33 - second measurement section). The test results can be found in Fig. 7.

The performed calculations show that the average change of the cutting edge height increase $\alpha$, in the tested section D1, as compared to a new edge, is smallest in the case of tool P1 working in the presence of industrial oil. The same result has been recorded for the pull broach P1 in the case 3 of comparative analysis of the changes of the rake angle $\gamma$. Analysing the other dimensional magnitudes (i.e. clearance angle $\alpha$, and the angle of the linear section of the chip groove $\beta$ ) in the same way as before, the smallest deviations from the model have been observed for pull broach P2 which had been working in the presence of lubricating oil with the modifying additive. The presented analysis neither excludes nor unambiguously proves positive or negative influence of the applied lubricants on the maintenance of the tool geometry or extension of its life. The analysis result is also influenced by the dimensional tolerance with which the tested pull broaches had been made. With the measurements performed with so high accuracy, the analysis result could be made false due to dimensional deviations adopted for the pull broaches or inaccurate execution of them.

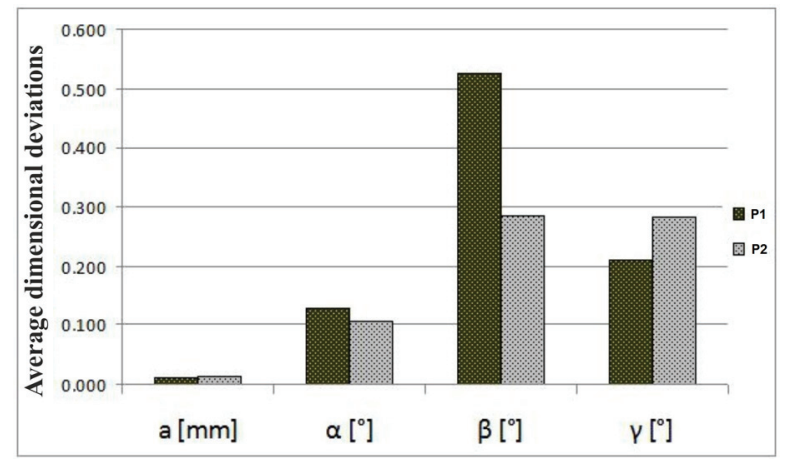

Fig. 7. Arithmetical average of dimensional deviations of the geometry of tools P1 and P2 on section D1.

The analysis of the tool wear by assessment of the changes of the cutting wedge geometry has been performed with use of microscopic examination of the rake face which is exposed to various kinds of changes (e.g. blunting, damages) resulting from high load during operation. Test results can be seen in Fig. 8 .

An analysis of the cutting edge rounding outline and the condition of the side surface of the broach wedges has proved positive influence of the exploitation additive on the improvement of P2 tool life by:

- more precise maintenance of the cutting edge geometry;

- burns not occurring in vast areas;

- lower number of laccretions;

- lack of significant traces of machining in accordance with the direction of it;

- lack of damages of the protective coating;

- lack of material chipping from the corner.

Microscopic examination of the rake face and the flank face has also been performed. The results can be found in Fig. 9.
The cutting edge wear of tool P1 is larger than that of the cutting edge of tool P2.

The roughness of the splineway surfaces made in the presence of the tested lubricant has also been measured. The measurements of the splineway surface roughness have been performed on randomly selected gear wheels. The average value of the roughness parameter $R a$ of a splineway lubricated in the manufacturing process has reduced from $0.71 \mu \mathrm{m}$ to $0.38 \mu \mathrm{m}$ after the application of a modified lubricant. Table 5 presents the value of average surface roughness measurements, according to $R a$ parameter, of splineways made in the presence of the lubricants under investigation.

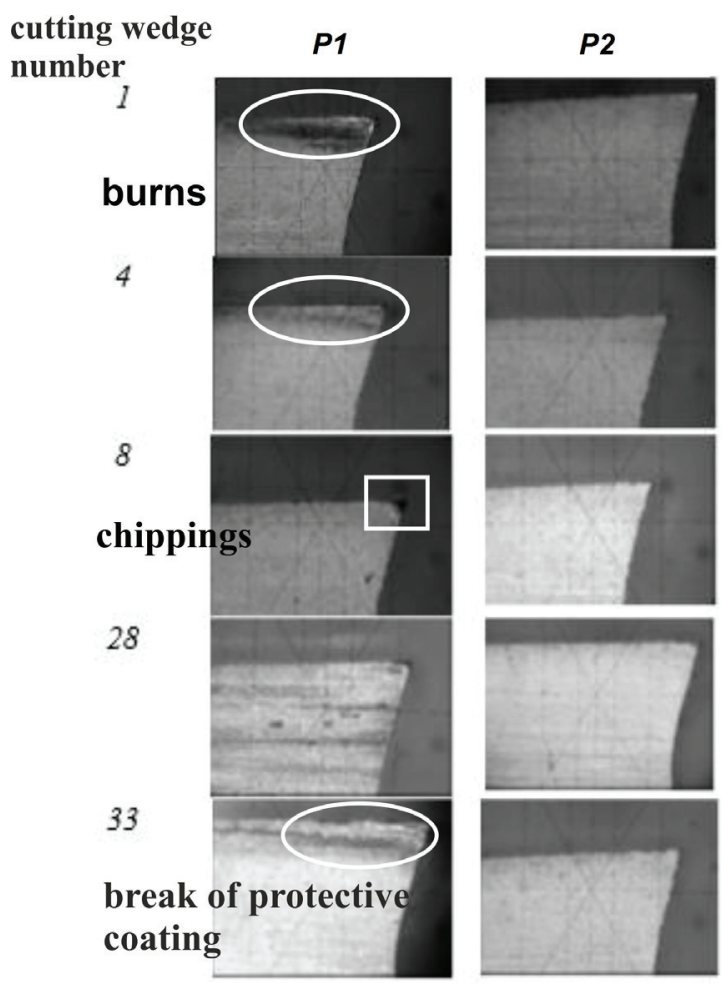

Fig. 8. Photographs of used pull broach cutting edges made during microscopic examination.

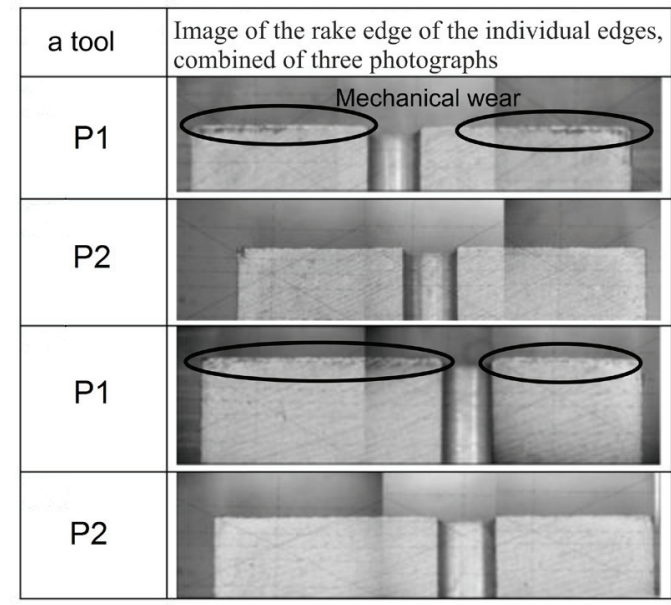

Fig. 9. A view of the rake face of the cutting edges.

The obtained results prove positive influence of the exploitation additive on improvement of the surface 
quality of machined splineways by reduction of the average value of the roughness parameter $R a$. The value of the $R a$ parameter has reduced by $47 \%$ with the use of modified lubricant.

Table 5. $R a$ roughness parameter of splineways executed with the application of various lubricants.

\begin{tabular}{|c|c|c|}
\hline $\begin{array}{c}\text { Measurement } \\
\text { number }\end{array}$ & $\begin{array}{c}\text { Industrial } \\
\text { lubricating oil } \\
\qquad R a\end{array}$ & $\begin{array}{c}\text { Modified } \\
\text { lubricating oil } \\
R a\end{array}$ \\
\hline $\mathrm{R}_{\mathrm{a}}$ average & $0.71 \mu \mathrm{m} \pm 0.04$ & $0.38 \mu \mathrm{m} \pm 0.01$ \\
\hline
\end{tabular}

\section{Conclusions}

The results of the tests of lubricating properties of the lubricants under examination do not unambiguously prove a positive influence of the exploitation additive on the improvement of all the indices of the lubricating properties. Some of those indices, i.e. the weld point $P z$, the highest not seizing load $P n$, and the index of wear under load $I_{h}$, do not show improvement as result of modification. On the other hand, an increase of the seizing load $P_{\mathrm{t}}$, and the limit wear load index $G_{o z}$, has been obtained. The increase of the limit wear load index has significantly improved the anti-wear properties of the modified oil.

The application of the modifying additive has influenced reduction of the tool wear. This effect has been obtained by:

- reduction of the value of the coefficient of friction between the flank face and the material being machined;

- reduction of the value of the coefficient of friction between the rake face and the formed chip;

- reduction of temperature in the cutting zone;

- occurrence of lower pressures and stresses during machining.

The performed exploitation tests prove positive influence of modification of metal machining oil on improvement of the surface quality of the splineway of a gear wheel made of casting bronze $\mathrm{CuSn} 12 \mathrm{Ni} 2$, by reduction of the average value of the roughness parameter $R a$. The $R a$ value has dropped by $47 \%$. As result of the modification, the durability of the cutting tool has also increased by $40 \%$.

\section{References}

1. R.W. Maruda, S. Legutko, G.M. Krolczyk, C. Lukianowicz, A. Stoic, Teh. Vjes. 22, 1219 (2015)

2. G.M. Krolczyk, J.B. Krolczyk, R.W. Maruda, S.Legutko, Measurement 88, 176 (2016)

3. S. Wojciechowski, P. Twardowski, M. Pelic, R.W. Maruda, S. Barrans, G. Krolczyk, Precis. Eng. 46, 158 (2016)

4. S. Wojciechowski, R.W. Maruda, P. Nieslony, G.M. Krolczyk, Int. J. Mech. Sci. 119, 360 (2016)
5. G.M. Krolczyk, R.W. Maruda, P. Nieslony, M. Wieczorowski, Measurement 94, 464 (2016)

6. R.W. Maruda, G.M. Krolczyk, P. Nieslony, S. Wojciechowski, M. Michalski, S. Legutko, J. Manuf. Process 24, 107 (2016)

7. R. Michalczewski, W. Piekoszewski, M. Szczerek, W. Tuszyński, Problems of Exploitation 1, 247 (2003) (in Polish)

8. R. Michalczewski, M. Szczerek, W. Tuszyński, Problems of Exploitation 4, 247 (2004) (in Polish)

9. R. Michalczewski, W. Piekoszewski,W. Szczerek, M. Tuszyński, Tribology 5, 81 (2007) (in Polish)

10. R. Michalczewski, W. Piekoszewski, M. Szczerek, W. Tuszyński, Tribology 6, 133 (2007) (in Polish)

11. R.W. Maruda, E. Feldsthein, S. Legutko, G.M. Krolczyk, J. Frict. Wear 36, 548 (2015)

12. M. Pasliecliko, K. Dziedzic. M. Barszcz, Powder Metall. Met. C 52, 469 (2013)

13. V. Fontanari, M. Benedetti, G. Straffelini, Ch. Girardi, L. Giordanino, Wear 302, 1520 (2013)

14. B.S. Unlu, E. Atik, J. Alloy. Compd. 489, 262 (2010)

15. T. Kucukomeroglu, G. Purcek, O. Saray, L. Kara, Jamme 30, 172 (2008)

16. S. Laber, K. Adamczuk, Tribology; Theory and Practice 6, 49 (2010) (in Polish)

17. K. Wieczorowski, S. Legutko, T. Kędzierski, ATMiA 2, 31 (2002) (in Polish)

18. A. Laber, Study of the use of exploitation additives to lubricating oils in tribological systems (Publishing House of Zielona Góra University, Zielona Góra, 2012) (in Polish) 